\title{
Comparison between Horizontal and Vertical Lamellate Patternators for Air-blast Sprayers
}

\author{
Marcello Biocca* and Pietro Gallo
}

\author{
CRA-ING Consiglio per la Ricerca e la sperimentazione in Agricoltura, Unità di Ricerca per l'Ingegneria Agraria. Via \\ della Pascolare, 16 - 00015, Monterotondo Roma, Italy
}

\begin{abstract}
Among the possible sources of environmental contamination by plant protection products, the use of air blast sprayers in orchards and vineyards can be very critical. The evaluation of the vertical distribution pattern is a crucial test to achieve a good quality of spray application. The aim of the paper was to compare the performance of a vertical lamellate patternator versus a horizontal lamellate patternator. For this aim, an experimental device that allows the use of the same patternator, mounting the lamellae either horizontally or vertically, was utilized. The results showed that using the patternator with vertical lamellae a greater amount of liquid, 25\%, was collected than using the horizontal lamellae under the same test conditions. This amount represented the $36.7 \%$ of the total sprayed volume. The performance of patternator may be related to the reduced disturbance of the air flow induced by vertical lamellae. Although the amount of liquid collection is not considered the only parameter to assess the quality of a patternator, this characteristic can improve the efficiency of the test, especially when low volume orchard sprayers are tested.
\end{abstract}

Keywords: Orchard sprayers, vertical pattern distribution.

\section{INTRODUCTION}

The calibration of sprayers is a crucial issue to achieve a high effectiveness in pesticide spray application. The ongoing European Directive 128/09 [1] on the sustainable use of pesticides gives a special attention to the application phase, including measures devoted both to the mandatory inspection of sprayers and to their calibration. During the calibration of orchard sprayers, a key point is to obtain a vertical pattern of liquid distribution that matches as correct as possible the tree's canopy. In fact, the equipment should "direct the spray only on the target (usually the tree crown) [2]", in order to reduce the off-target (drift and run-off) and to optimize the chemical treatment.

Different methods are ordinarily employed to assess the vertical distribution pattern (i.e. the amounts of liquid sprayed at various heights). They include: image analysis of water sensitive papers [3-5], analysis of droplets by laser or ultrasonic techniques [6,7], assessment of deposits (or tracers) on numerous passive adsorbent samplers [8-10] computational fluid dynamics [11], thermography [12] and vertical patternators.

Vertical patternators sample the spray at different heights by intercepting and collecting the droplets with various tools as metallic trays, plates covered with adsorbent material, funnel shaped collector and lamellae, that can be

\footnotetext{
*Address correspondence to this author at the CRA-ING Consiglio per la Ricerca e la sperimentazione in Agricoltura, Unità di Ricerca per l'Ingegneria Agraria. Via della Pascolare, 16 - 00015, Monterotondo Roma, Italy; Tel: +39 0690675217; Fax: +39 0690625591;

E-mai: marcello.biocca@entecra.it
}

mounted horizontally (very common) or vertically $[2,13-$ 16]. The patternators are employed both for the certification of new sprayers and for the testing of equipment in use during their periodical inspection and calibration [17]. Other researchers studied the performance of patternators or compared the obtained assessment of spray with the real deposit on the plants $[18,19]$.

In particular, the lamellate patternators are capable of collecting "sprayed liquid by means of the reduction of air speed [2]" that occurs when the air flow passes through the lamellae. In such a way, the droplets rapidly slow down and fall in the bottom of the box that contains the lamellae, where a plastic duct discharges the liquid into a measuring tube.

The aim of this paper was to compare the performance of a lamellate patternator mounting the lamellae horizontal or vertical, in order to obtain a device reliable and effective during testing of sprayers. Specific tests devoted to optimize the design of this category of patternators are lacking and this paper refers to original results useful for the manufacturing of testing equipment.

\section{MATERIALS AND METHODS}

To compare the liquid collection of the vertical patternators, an experimental device was realized and utilized in the trials. It consists of a bench where a single patternator is mounted, consisting of a metallic box with the lamellae. The box can rotate on the test bench and in such a way the lamellae can work either horizontally or vertically (Fig. 1). The box consists of 20 aluminum lamellae spacing $2.5 \mathrm{~cm}$; the interception area is $0.09 \mathrm{~m}^{2}$. Then, moving the box on the 

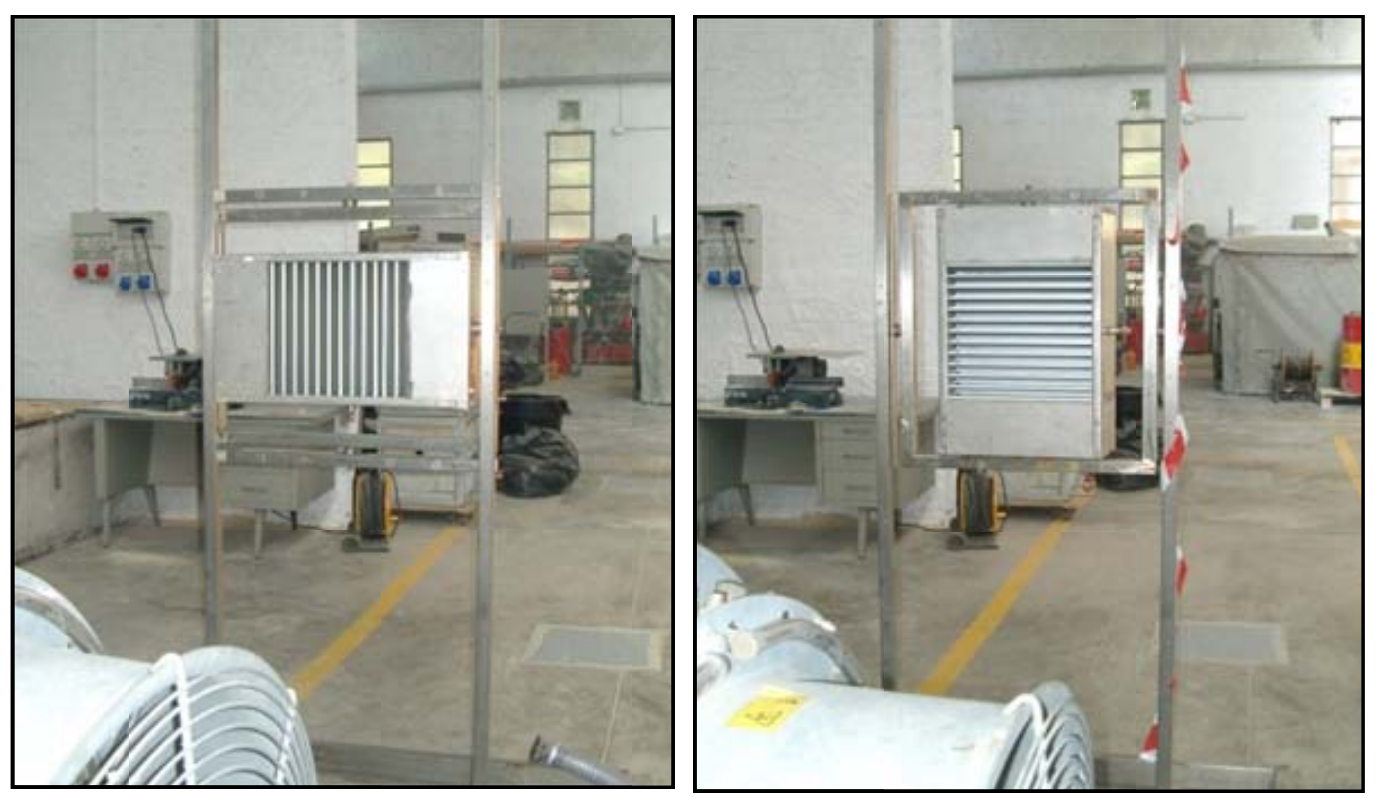

Fig. (1). The test bench with the lamellate patternator mounted vertically (left) and horizontally (right).

Table 1. Sprayer setups.

\begin{tabular}{|c|c|c|c|c|}
\hline Setup & Nozzle & Orifice Diameter & Pressure & Total Flow Rate \\
\hline \hline $\mathrm{N}^{\circ}$ & & $(\mathrm{mm})$ & $(\mathrm{kPa})$ & 15 \\
\hline 1 & $5(2+3)$ & 2.0 and 1.5 & 10 & 28.7 \\
\hline 2 & $6(2+4)$ & 2.0 and 1.5 & 15 & 33.2 \\
\hline 3 & $6(2+4)$ & 2.0 and 1.5 & 10 & 27.6 \\
\hline 4 & 6 & 1.5 & 15 & 26.5 \\
\hline 5 & 6 & 1.5 & & 26.6 \\
\hline
\end{tabular}

frame, it is possible to place the patternator at different heights, from $370 \mathrm{~mm}$ to $3070 \mathrm{~mm}$.

Each patternator position (i.e. vertical or horizontal lamellae) "was tested for liquid collection performances with different sprayed water volumes [2]", placing the patternators at ten different heights (center of the patternator: from $0.37 \mathrm{~m}$ to $3.07 \mathrm{~m}$, spacing $300 \mathrm{~mm}$ ) in a set of trials and at five different heights in a second set of trials (from 0.67 to 3.07 , spacing $600 \mathrm{~mm}$ ). "The amount of collected water was measured at least three times [2]" for each test.

"All the trials were carried out using a trailed orchard sprayer (Nobili Geo 75-600 T) spraying the bench only with the right side of the sprayer and placing the sprayer at $1.5 \mathrm{~m}$ from the bench [2]". The time of sampling was recorded by means of a chronometer. The sprayer was equipped with ceramic cone nozzle, with discs (orifice diameter: 1.5 and 2 $\mathrm{mm}$ ) and steel swirl plates (orifice diameter: 1.2 and $2 \mathrm{~mm}$ ). The sprayer was adjusted with five different setups, obtained varying the number and type of nozzles and "setting the pressure to $1000 \mathrm{kPa}$ and $1500 \mathrm{kPa}$ [2]" (10 and $15 \mathrm{bar}$ ) as reported in Table $\mathbf{1}$. The same orientation and position of nozzles were carefully maintained during each trial.
Moreover, the air velocity in front and behind the patternators (with horizontal and vertical lamellae) was compared to the corresponding velocity value measured without the patternator box mounted (undisturbed air flow). The measures were carried out for 5 test heights. For these measures, "an anemometer Schiltknecht Micro Mini Air 4 (with each measure as an integration of 30 seconds period of measurement) [2]" was employed.

The obtained values were then compared with an analysis of variance (Anova) procedure computed with the software $\mathrm{R}$ [20]. The Anova was performed on the total collected amounts at the different heights, in terms of collected water per minute. The data underwent a logarithmic transformation in order to obtain a normal distribution.

\section{RESULTS}

The results are expressed in terms of collected liters of water per 1 square meter of intercepting patternator surface per minute of spraying $\left(\mathrm{L} \mathrm{min}^{-1} \mathrm{~m}^{-2}\right)$ and in terms of the ratio of collected water by sprayed water (flow rate of sprayer, $\mathrm{L} \min ^{-1}$ ). 
Table 2. Results of Anova for comparison of lamellae interception capability.

\begin{tabular}{|c|c|c|c|c|c|}
\hline & D.f. & Sum Sq. & F value & Pr(>F) & Significance. \\
\hline \hline Lamellae & 1 & 0.64 & 10.37 & 0.00146 & $* *$ \\
\hline Flow rate & 4 & 3.09 & 12.54 & $2.99 x 10^{-9}$ & $* * *$ \\
\hline Interaction (lamellae x flow rate) & 4 & 0.11 & 0.45 & 0.77031 & \\
\hline Residuals & 230 & 14.18 & & \\
\hline
\end{tabular}

Significance codes: 0 ‘***’ 0.001 ‘**’.
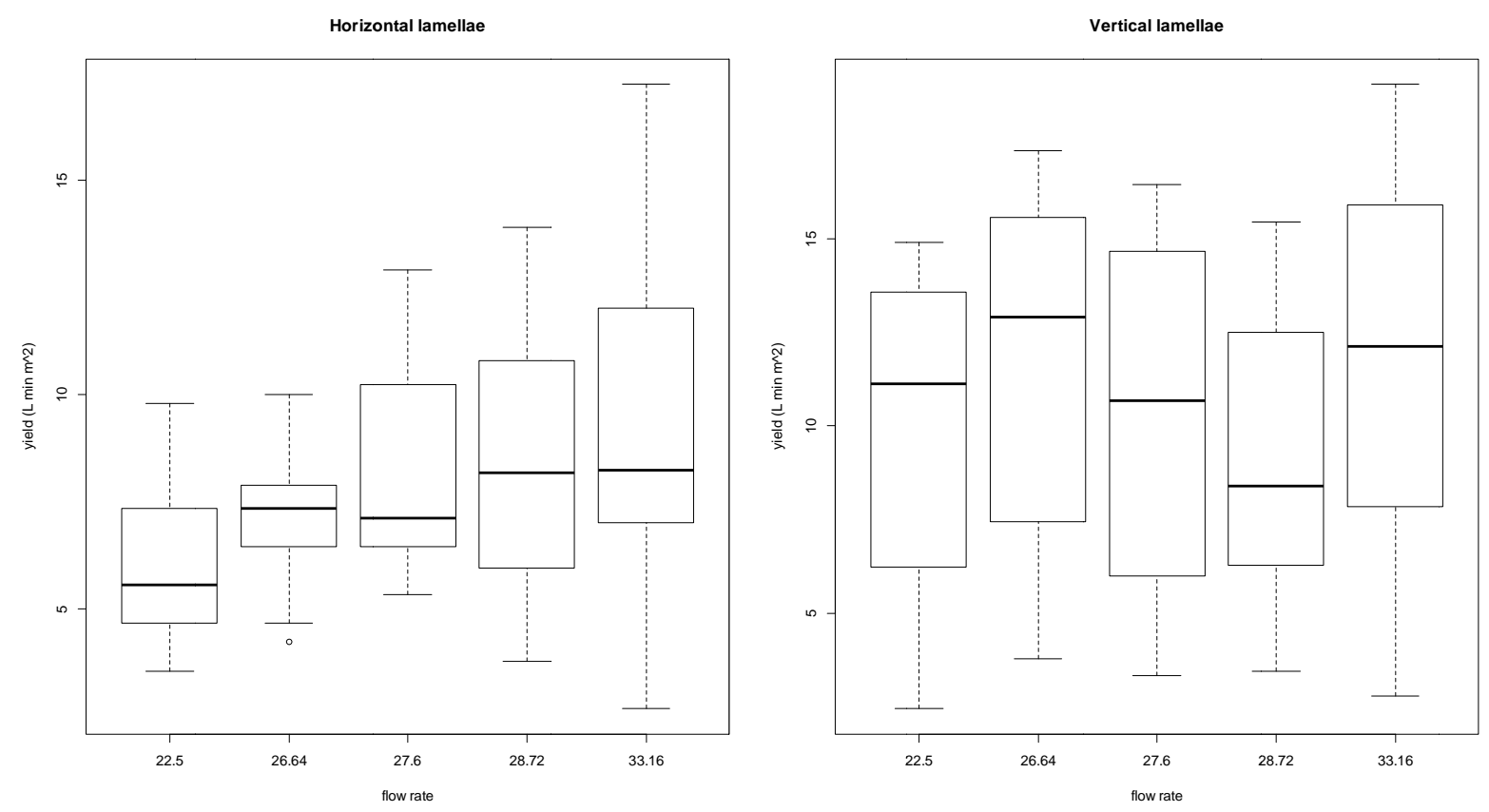

Fig. (2). Average collected water $\left(\mathrm{L} \mathrm{min}^{-1} \mathrm{~m}^{-2}\right)$ with horizontal and vertical lamellae by sprayer configurations (bottom box $=1^{\text {st }}$ quartile; top box $=3^{\text {rd }}$ quartile; band $=$ median; whiskers $=$ maximum and minimum $)$.

As general result (average of total liquid collection in 14 tests in different ( with- sample size equal to 125 for vertical and 115 measurements for horizontal) we obtained that, under the test conditions, the vertical lamellate patternator was able to intercept $25.0 \%$ liquid more than horizontal lamellae (i.e. $10.8 \mathrm{~L} \mathrm{~min}^{-1} \mathrm{~m}^{-2}$ of collected water in vertical vs. $8.1 \mathrm{~L}$ $\min ^{-1} \mathrm{~m}^{-2}$ in horizontal, corresponding respectively to $36.7 \%$ and $27.7 \%$ of the total sprayed volume).

The Anova shows statistically significant difference (with a probability level greater than 99\%) between vertical and horizontal lamellae (Table 2), and also a significant difference in terms of collection capability with different sprayer configurations. This last result obviously depends on the differences in flow rates that in our experiment were set to vary from 22.5 to $33.2 \mathrm{~L} \mathrm{~min}^{-1}$. The analysis shows also that no interaction occurs between the two analyzed factors. In other words, the combination of horizontal and vertical lamellae with different levels of flow-rate does not show any synergistic effect. The average performance of the two systems in terms of rate of collection (i.e. $\mathrm{L} \mathrm{min}^{-1}$ per 1 square meter of patternator) is shown in the Fig. (2).
In Fig. (3), we report the results of liquid collection in the two systems at different heights, where it is possible to note that the two systems show different results especially at lower flow-rates and at lower test heights.

In Fig. (4), the average of air speeds recorded in front and behind the patternator shows that the vertical lamellae cause less reduction of air speed than the horizontal lamellae. The undisturbed air flow (without patternator) data was derived from a single measurement. In other terms, the flow of air generated by the sprayer's fan is less disturbed by the lamellae placed in vertical position. However, this difference, after an analysis of the variance (not reported here), was not statistically significant.

\section{CONCLUSION}

The results showed that using the patternator with vertical lamellae a greater amount of liquid was collected than using the horizontal lamellae under the same test conditions.

Since it is not possible to compare the obtained vertical patterns to a single reference pattern (i.e. real deposit on the 


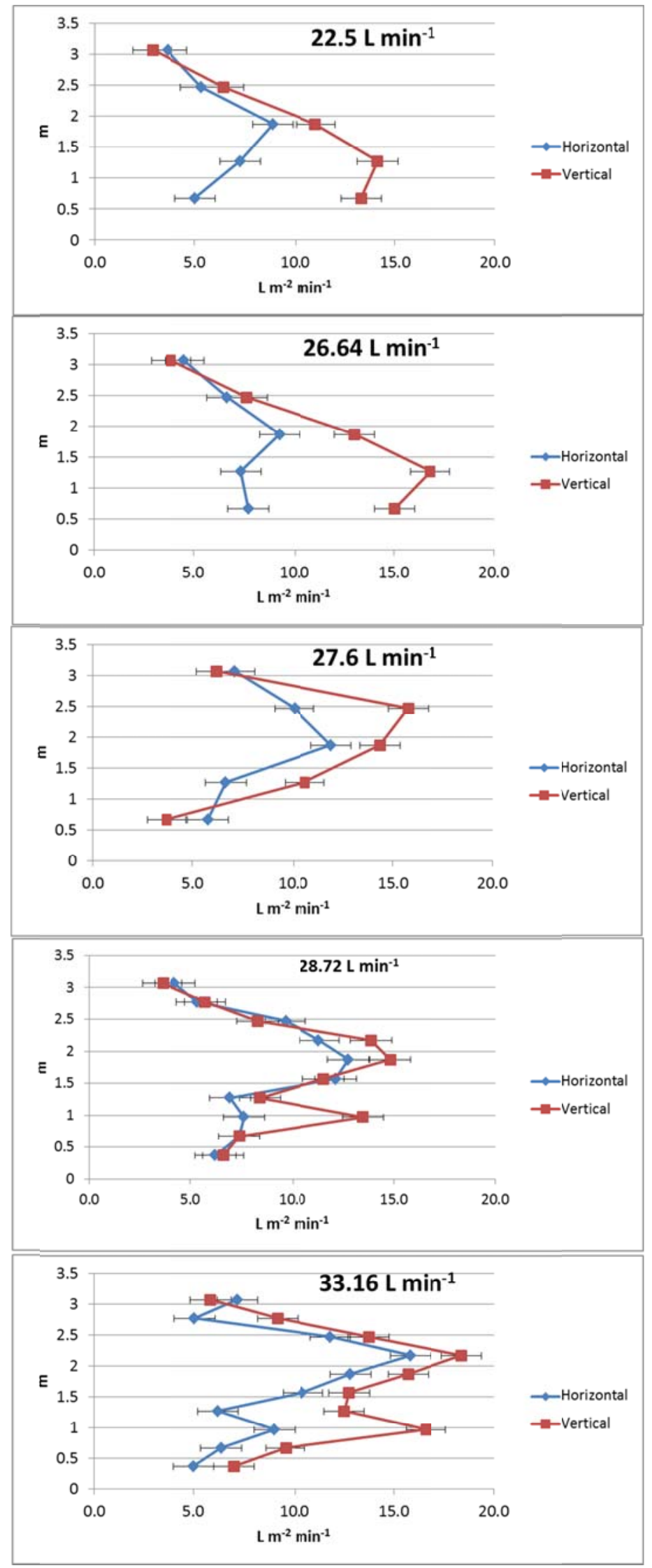

Fig. (3). The vertical patterns obtained with the two patternatorsat the different flow-rates $\left(\mathrm{L} \mathrm{min}^{-1} \mathrm{~m}^{-2} \pm\right.$ s.e. $)$. 


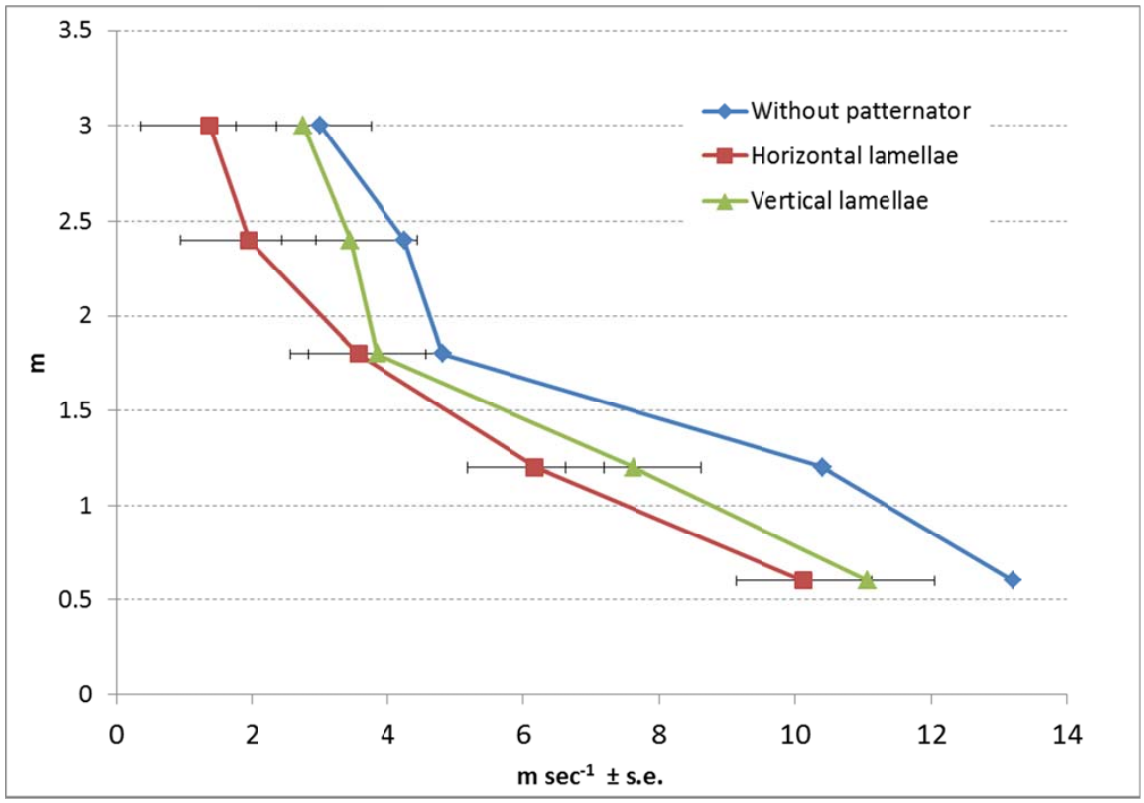

Fig. (4). The air speed pattern $\left(\mathrm{m} \mathrm{sec}^{-1} \pm\right.$ standard error) at the different eights with the two patternators mounted, in comparison with the undisturbed air flow (without patternator).

leaves) it is necessary to choose some objective parameters to compare the results. A possible solution is to assess the capacity of the patternator in terms of quantity of collected liquid, an index that explains the efficiency of the sampler.

"Although the data of liquid collection is not considered the only parameter to assess the quality of a patternator, this characteristic could be very useful especially when [2]" low volume orchard sprayers are tested [13].

"The best performance of vertical lamellae in terms of total liquid collection [2]" may be explained with the fact that the vertical lamellae cause less disturbance of the flow air around the patternator with respect to horizontal ones. In this way, the air flow can carry a larger amounts of droplets, with less interference due to a "shield" effect that the patternator can likely act.

The results may be useful to design and develop effective test benches, capable of designing the vertical pattern distribution of sprayers in a wider range of sprayer's setups.

\section{CONFLICT OF INTEREST}

The authors confirm that this article content has no conflict of interest.

\section{ACKNOWLEDGMENTS}

The authors are grateful to Giancarlo Imperi for his assistance during trials.

\section{REFERENCES}

[1] European Directive 2009/128/EC of the European Parliament and of the Council of 21 October 2009 establishing a framework for Community action to achieve the sustainable use of pesticides, 24.11.2009. Official Journal of the European Union L 309/71-86.
[2] Biocca M, Mattera E, Imperi G. A new vertical patternator to evaluate the distribution quality of vineyards and orchards sprayers. FRUTIC 05, Information and technology for sustainable fruit and vegetable production, 2005 Sep 12-16, Montpellier: France, pp. 653-660.

[3] De Moor A, Langenakens J, Vereecke E, Jaeken P, Lootens P, Vandecasteele P. Image analysis of water sensitive paper as a tool for the evaluation of spray distribution of orchard sprayers. Asp Appl Biol 2000; 57: 329-42.

[4] Salyani M, Zhu H, Sweeb R.D, Pai N. Assessment of spray distribution with water-sensitive paper. Agric Eng Int: CIGR Journal 2013; 15 (2): 101

[5] Mangado J, Arazuri S, Arnal P, Jarén C, López A. Measuring the Accuracy of a Pesticide Treatment by an Image Analyzer. Procedia Technol 2013; 8: 498-502.

[6] Miralles A, Gorretta N, Dusserre-Bresson L, et al. Results of a European programme to compare methods used to test orchard sprayers 1. EPPO Bull 1996; 26(1): 59-68.

[7] Tekeloglu O, Parkin S. A new technique for the measurement of the spatial distribution of sprays in air-jets. Assoc Appl Biol; 2002: 435-42.

[8] Miller DR, Yendol WE, McManus ML. On the field sampling of pesticide spray distributions using Teflon spheres and flat cards. J Environ Sci Health Part B 1992; 27(2): 185-208.

[9] Pergher G. Recovery rate of tracer dyes used for spray deposit assessment. Trans ASAE 2001; 44(4): 787-94.

[10] Hoffmann WC, Hewitt AJ, Barber JAS, Kirk IW, Brown JR. Field swath and drift analyses techniques. Pap Number AA03-007, 2003.

[11] Dekeyser D, Duga AT, Verboven P, Endalew AM, Hendrickx N, Nuyttens D. Assessment of orchard sprayers using laboratory experiments and computational fluid dynamics modelling. Biosyst Eng 2013; 114(2): 157-69.

[12] Menesatti P, Biocca M, D'Andrea S, Pincu M. Thermography to analyze distribution of agricultural sprayers. Quant Infrared Thermogr J 2008; 5(1): 81-96.

[13] Ade G, Venturi P. Valutazioni su alcuni sistemi di controllo della distribuzione in verticale delle irroratrici da frutteto. Rivista di Ingegneria Agraria 1995; 4 : 230-9.

[14] Pergher G, Gubiani R. A comparison of methods for assessing vertical spray distributions from air-assisted sprayers. EPPO Bull 1997; 27(2-3): 227-34.

[15] Pascuzzi S, Guarella P, Percoco A, Guario A, Ganzelmeier H, Wehmann HJ. Test-bench and computer-aided measurement system for checking and calibrating spraying machines used in "tendone"-trained vineyards. First European Workshop on Standardised 
Procedure for the Inspection of Sprayers in Europe-SPISE Braunschweig, 2004 April 27-29. Mitt Biol Bundesanst LandForstwirtsch 2004; 397: 133-42

[16] Gil E, Badiola J. Design and verification of a portable vertical patternator for vineyard sprayer calibration. Appl Eng Agric 2007; 23(1): $35-42$.

[17] Gil E. Inspection of sprayers in use: a European sustainable strategy to reduce pesticide use in fruit crops. Appl Eng Agric 2007; 23 (1): 49-56.

[18] Balsari P, Ade G, Cerruto E, et al. Are vertical spray patterns an efficient instrument that can improve the adjustment of air-assisted sprayers in vineyard? First European Workshop on Standardised Procedure for the Inspection of Sprayers in Europe-SPISE Braunschweig, 2004. Mitt Biol Bundesanst Land-Forstwirtsch 2004; 397: 146-153.

[19] Pergher G. Field evaluation of a calibration method for air-assisted sprayers involving the use of a vertical patternator. Crop Prot 2004 23(5): 437-46.

[20] Team RC. R: a language and environment for statistical computing 2013. R Foundation for Statistical Computing, Vienna: Austria ISBN 3-900051-07-0; 2013.

Received: March 05, 2014

Revised: May 26, 2014

Accepted: June 04, 2014

(C) Biocca and Gallo; Licensee Bentham Open.

This is an open access article licensed under the terms of the Creative Commons Attribution Non-Commercial License (http://creativecommons.org/licenses/by-nc/3.0/) which permits unrestricted, non-commercial use, distribution and reproduction in any medium, provided the work is properly cited. 